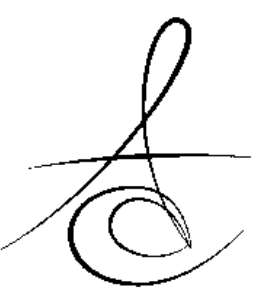

\title{
LİTERATÜRDE IN VITRO ELEKTRONİK APEKS BULUCU ÇALIŞMALARINDA KULLANILAN ORTAM ÇEŞİTLERİ: BİR DERLEME
}

\section{MEDIA VARIETIES USED IN IN VITRO ELECTRONIC APEX LOCATORS STUDIES IN LITERATURE: A REVIEW}

Uzm. Dt. Hamza CUDAL*

Doç. Dr. Tuğrul ASLAN*

\author{
Doç. Dr. Yakup ÜsTÜN*
}

\author{
Makale Kodu/Article code: 4382 \\ Makale Gönderilme tarihi; 04.05 .2020 \\ Kabul Tarihi: 02.10.2020 \\ DOI : $10.17567 /$ ataunidfd. 804415
}

Hamza Cudal : ORCID ID: 0000-0002-1195-7196

Tuğrul Aslan : ORCID ID: 0000-0002-5055-1551

Yakup Üstün: ORCID ID: 0000-0002-9290-5661

\section{öz}

Kök kanalı tedavisinde uzun vadeli başarı, kök kanal sisteminin en uygun şekilde dezenfeksiyonu, preparasyonu ve doldurulması ile mümkündür. Kanal tedavisinin sonlanacağı yeri belirlemek tedavinin en önemli basamaklarından biridir. Preparasyonun taşkın yapılması post-operatif ağrıyı artırabilirken, kısa kök kanal dolgusu yeterli dezenfeksiyonun yapılamamasına sebep olabilir. Bu aşamada, elektronik apeks bulucular (EAB) yüksek bir doğruluk seviyesinde apikal daralımın yerinin tespit edilmesine yardımcı olmaktadırlar. Çalışma prensibi genel olarak dokular arasındaki empedans farkının tespitine dayanmaktadır. Elektronik apeks bulucu cihazların, hastada kullanılmadan önce doğruluğunun araştırıması başarılı tedaviler açısından önemlidir. Aynı zamanda, apeks bulucuların ölçme başarısını etkileyebilecek kanal içi solüsyonların, ilaçların, enstrümanların in vitro çalışmalarla değerlendirilmesi önemlidir. Piyasada bulunan apeks bulucuların ölçüm doğruluklarını değerlendiren birçok in vitro çalışma yapılmıştır. Bu in vitro çalışmalar gerçekleştirilirken periapikal dokuları taklit edecek elektro-iletken test ortamları gereklidir. Kullanılan test ortamları jelatin, aljinat, agar agar, salin solüsyonu, çiçek süngeridir. Bu derlemenin amacı, literatürdeki in vitro çalışmalarda kullanılan test ortamları hakkında bilgi vermektir.

Anahtar kelimeler: endodonti, kök kanal tedavisi, diş apeksi.

\section{ABSTRACT}

Long-term success in root canal treatment is possible with appropriate disinfection, preparation and filling of the root canal system. Determining the ending point of root canal therapy is one of the most important steps of the treatment. While overpreparation can increase the post-operative pain, short root canal filling may cause inadequate disinfection. At this point, electronic apex locators (EAL) help to locate the apical constriction with high accuracy level. The principle of operation is generally based on the detecting the impedance difference between tissues. It is important to investigate the accuracy of electronic apex locators before using them in patients with regard to successful treatments. To evaluate the intra-canal solutions, medicaments, instruments, which may affect the measuring success of apex locators, is important by means of in vitro studies. Many in vitro studies have been done to evaluate the accuracy of apex locators on the market. Electroconductive test environments that mimic periapical tissues are required when performing these in vitro studies. The test media used are gelatin, alginate, agar agar, saline solution, flower sponge. The purpose of this review is to provide information about in vitro test environments used in the literature.

Keywords: endodontics, root canal therapy, tooth apex.

*Erciyes Üniversitesi, Diş Hekimliği Fakültesi, Endodonti Anabilim Dalı, Kayseri.

Kaynakça Bilgisi: Cudal H, Aslan T, Üstün Y. Literatürde ın vitro elektronik apeks bulucu çalışmalarında kullanılan ortam çeșitleri: bir derleme. Atatürk Üniv Diş Hek Fak Derg 2021; 31: 454-8.

Citation Information: Cudal H, Aslan T, Ustun Y. Media varieties used in in vitro electronic apex locators studies in literature: a review. J Dent Fac Atatürk Uni 2021; 31: 454-8.

\section{GİRİ̧̧}

Başarılı kök kanal tedavisi, kök kanalının yeterli miktarda şekillendirilmesi, dezenfeksiyonu ve ardından üç boyutlu olarak doldurulabilmesine bağlıdır. Bunun için apikal daralımın yerinin doğru olarak belirlenmesi gerekmektedir. Apikal daralma, minör apikal çap ola- rak da bilinmektedir. ${ }^{1}$ Kök kanal tedavisinin başarısını en yüksek noktaya çıkarabilmek için kanal enstrümanları, irrigasyon solüsyonları ve kanal dolgu materyalleri apikal daralım noktasının ötesine geçmemelidir. ${ }^{2}$

Elektronik apeks bulucu (EAB) cihazlar çalışma uzunluğu tespiti için günümüzde önemli araçlar haline

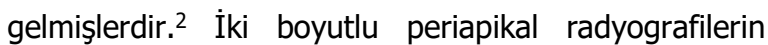


apikal daralımı belirlemedeki bazı dezavantajlarının üstesinden gelmek noktasında EAB'ler faydalı bir yardımcıdır. ${ }^{3}$ Klinik olarak, çoğu vakada, gerçek apikal daralım noktası radyografik apeks ile çakışmaz ve EAB'ler kullanılmadığında yanlış çalışma uzunluğu tespiti yapılabilir. ${ }^{4}$

İlk EAB, $1918^{\prime}$ de Custer $^{5}$ tarafından tanıtılmıştır ve $1^{1962}$ 'de Sunada $^{6}$ tarafından geliştirilmiştir. Apeks bulucuların birinci nesli sabit elektrik direnci, ikinci nesli tek elektrik akımının dokulardaki empedans farkı ve üçüncü nesli dokuların iki farklı elektrik akımındaki empedans farkına dayanarak çalışmaktadır. Dördüncü nesil apeks bulucular ise, iki farklı frekans arasında orantı kurarak apikal daralım noktasını belirlemektedir. ${ }^{7}$ Pek çok firmanın ürettiği farklı tiplerde EAB'ler kullanıma sunulmuştur. Bu cihazların farklı klinik koşullar altında ölçüm hassasiyetlerini değerlendiren pek çok çalışma literatürde yerini almıştır. ${ }^{8-10} \mathrm{Bu}$ çalışmalar hem in vivo ${ }^{11-13}$, hem de in vitro ${ }^{14-16}$ olarak gerçekleştirilmiştir.

Farklı EAB'lerin farklı kullanım yöntemleri bulunmakla beraber, EAB'lerin genel olarak kullanım şekli şu şekildedir: Çekilmiş dişler periapikal dokuları taklit eden elektro-iletken ortamlara gömülür. Hazırlanmış olan düzenekte eğe kanala yerleştirilir ve dudak klipsi elekro-iletken ortama temas ettirilerek devre tamamlanır.,17 Üretici firmanın kullanım klavuzuna göre, eğe apikal daralıma ulaşınca eğenin stoperi referans noktasına göre ayarlanarak boy ölçümü yapılır ve çalışma boyu belirlenir. ${ }^{18}$ Hazırlanan tüm modellerde dudak klipsi ile diş arasındaki mesafenin sabit tutulması çalışmanın güvenilirliği açısından önemlidir. ${ }^{7}$

EAB'lerin in vitro değerlendirilmesi ile ilgili literatürdeki çalışmalarda insan dokularının empedans değerlerini taklit edebilen diş gömme ortamları aşağıdaki gibi sıralanabilir: Jelatin, aljinat, salin solüsyonu, agar agar ve çiçek süngeri. Aşağıda bu ortamlardan ve literatürde kullanıldıkları in vitro çalışmalardan kısaca bahsedilmiştir:

\section{Jelatin}

Lifli protein içeren kemik, kıkırdak ve deride olan kollajenin, kısmi hidrolizi ile elde edilen çözünür bir protein bileşiğidir. ${ }^{19}$ Şişme ve çözünürlük gibi temel özelliklerinin yanı sıra, jel oluşumu, kalınlaşma, su bağlama kapasitesi, emülsiyon, köpük oluşumu ve stabilizasyonu, yapışma ve kohezyon, koruyucu kolloid fonksiyonu ve film oluşturma kapasitesi vardır. ${ }^{20} \quad 1987$ 'de Nahmias ve ark. ${ }^{21}$ ve 1993 'te Donelly ${ }^{22}$ tarafından in vitro apeks bulucu çalışmalarında kullanımı önerilmiştir. Literatürde test ortamı olarak jelatinin kullanıldığı bazı çalışmalara rastlanmaktadır. Baldi ve ark. yaptıkları bir araştırmada Root ZX (J. Morita, Tokyo, Japonya) apeks bulucuyu kullanarak, farklı test ortamlarının (aljinat, agar agar, çiçek süngeri, jelatin, salin solüsyonu) ölçüm doğruluğu üzerine etkisini araştırmışlardır. Jelatinin kullanımında gerçek kanal boyutuna göre, elektronik ölçümlerde $0,5 \mathrm{~mm}$ ile 1,5 mm arasında kısa ölçümler almışlardır. ${ }^{7}$ Guise ve ark. yaptıkları bir in vitro çalışmada, test ortamı olarak jelatin kullanmışlardır ve EAB'nin [Root ZX 2 (J. Morita, Tokyo, Japonya), Elements (SybronEndo, Glendora, $A B D$ ) ve Precision (Brasseler, Savannah, $A B D$ )] ölçüm etkinliğini değerlendirmişlerdir. Çalışma sonucunda, Root ZX'in diğerlerine göre anlamlı derecede doğru sonuçlar verdiğini bulmuşlardır. ${ }^{23}$ Mull ve ark., farklı kanal içi solüsyonların varlığında iki farklı apeks bulucunun etkinliklerini değerlendirmişlerdir ve çalışmalarında test ortamı olarak jelatin kullanmışlardır. Çalışma sonucunda, Sybron Mini (SybronEndo, Anaheim, ABD) apeks bulucunun sodyum hipoklorit ve klorheksidin varlığında Root XZ'ten daha doğru sonuçlar verdiğini bulmuşlardır. ${ }^{24}$

\section{Aljinat}

Hidrokolloid sınıfında bulunan aljinat, gıda, kimya ve ilaç endüstrilerinde sıklıkla kullanılmaktadır. ${ }^{25}$ Aljinatlar kahverengi deniz yosunlarından elde edilen $\beta$-D-mannuronik asit ve a-L-guluronik asitten oluşan polisakkaritlerdir. ${ }^{26}$ Aljinat jel partikülleri, biyolojik olarak uyumlu, toksik olmayan, biyolojik olarak parçalanabilir, ucuz ve üretimi kolay maddelerdir. ${ }^{25}$ Aljinatın içeriği test ortamının dirençli, sert ve pürüzsüz dokulu bir yüzey oluşturmasını sağlar. Aljinat, sert kıvamına rağmen iyonların dolaşmasına izin verir. ${ }^{7} \mathrm{Bu}$ sebeplerden ötürü, in vitro $\mathrm{EAB}$ çalışmalarında en çok kullanılan test ortamı olmuştur. ${ }^{27-29}$ Baldi ve ark. EAB'lerin farklı test ortamlarındaki etkinliğini karşılaştırdıkları çalışmalarında gerçek kanal boyutuna en yakın elektriksel ölçümü aljinatın kullanımında elde etmişlerdir. ${ }^{7}$ Lipsky ve ark. 2012 yılında gerçekleştirdikleri bir çalışmada, çekilecek dişlerin elektronik çalışma boyu ölçümlerini hasta ağzında ve aynı dişlerin çekildikten sonraki ölçümlerini in vitro olarak gerçekleştirip birbirleriyle karşılaştırmışlardır. Bu çalışmada, test ortamı olarak aljinat kullanmışlardır ve in vitro ve in vivo ölçümlerin çok yakın değerler verdiğini bildirmişlerdir. ${ }^{30}$ Gehlot ve ark. 2016 yılında aljinat test ortamını kullanarak paslanmaz çelik eğeler ile $\mathrm{Ni}-\mathrm{Ti}$ eğelerin farklı apeks bulucuların ölçüm kabiliyetlerini [Root ZX, Propex Pixi (Dentsply Maillefer, Ballaigues, İsviçre), Elements Apex Locator, SybronEndo Mini Apex Loca-

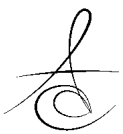


tor] nasıl etkilediğini araştırmışlardır. Root ZX'in Ni-Ti eğelerle ve SybronEndo Mini'nin de paslanmaz çelik eğeler ile daha doğru sonuçlar verdiğini bulmuşlardır. ${ }^{31}$ 2019 yılında Khatri ve ark. ${ }^{32}$ yaptıkları çalışmada, aljinat kullanarak apeks bulucuların [iPex (NSK, Japonya), VDW Gold (VDW, Munich, Almanya)] perforasyon bölgesini belirlemedeki etkinliğini ve aynı zamanda sodyum hipoklorit ve klorheksidinin EAB'lerin ölçüm yeteneklerini nasıl etkilediğini araştırmışlardır. Çalışma sonucunda kuru kanallarda VDW Gold gerçek değere yakın bir sonuç verirken, en ideal sonucun klorheksidin varlığında iPex'ten alındığı bildirilmiştir. ${ }^{32}$ Çiçek ve Bodrumlu aljinat test ortamını kullanarak farklı solüsyonların varlığında Raypex 5 ve Propex 2'nin ölçüm kabiliyetlerini değerlendirmişlerdir. Propex 2'nin, Raypex 5'e göre daha güvenilir sonuçlar verdiğini bulmuşlardır. ${ }^{33}$

\section{Salin Solüsyonu}

Salin solüsyonu içinde; sodyum klorür, potasyum klorür, disodyum fosfat, potasyum fosfat ve damıtılmış su bulunduran bir çözeltidir.7 İlk kez 1983'te Ushiyama tarafından salin solüsyonunun in vitro apeks bulucu çalışmalarında kullanımı önerilmiştir. ${ }^{34}$ Baldi ve ark. test ortamı olarak $\% 0,9^{\prime}$ luk salin ile diğer test ortamlarını (aljinat, agar agar, çiçek süngeri, jelatin) karşılaştırdıkları çalışmalarında gerçek diş çalışma uzunluğundan $0,5 \mathrm{~mm}$ ile $1,5 \mathrm{~mm}$ arasında kısa ölçümler bulmuşlardır. ${ }^{7}$ Zand ve ark. çalışmalarında Root ZX ve Novapex (Forum Technologies, Rishon Lezion, İsrail) apeks bulucuların etkinliğini değerlendirirken test ortamı olarak salin solüsyonunu kullanmışlardır. Her iki EAB'nin de apikal 1 mm'de \%90'ın üzerinde doğruluk göstererek başarılı bulunduklarını bildirmişlerdir. ${ }^{35}$ Nekoofar ve ark. farklı alaşımlardan yapılmış kanal eğelerinin, Neosono Ultima EZ (Amadent, Cherry Hill, ABD) apeks bulucu cihazın doğruluğuna etkisini araştırmışlardır. Bu çalışmada test ortamı olarak fosfat tamponlu salin ile \%2 agar agar kullanmışlardır. Cihazın doğruluğu; paslanmaz çelik eğelerde \%91, Ni-Ti eğelerde \%94 bulunmuş ve aralarında anlamlı bir fark olmadığı bildirilmiştir. ${ }^{36}$

\section{Agar Agar}

Agar agar, kırmızı deniz yosununun işlenmesi ile sentezlenen jöle benzeri bir biyopolimerdir. ${ }^{37}$ Birçok özelliğinden dolayı, gıda, kozmetik, ilaç, biyomedikal ve biyoteknoloji endüstrilerindeki uygulamalar için ticari olarak üretilmektedir. ${ }^{37}$ Dental alanda genellikle ölçü duplikasyonunda kullanılan bir materyaldir. ${ }^{38}$ Baldi ve ark.'nın yaptıkları çalışmada gerçek kanal boyutu ile agar agar ortamında ölçülen elektronik sonuçlar arasında $0,0 \mathrm{~mm}$ ile $1,5 \mathrm{~mm}$ arasında farklar bulunmuştur. ${ }^{7}$ Ak ve ark. tarafından yapılan çalışmada, periapikal dokuları iyi taklit ettiği için, test ortamı olarak agar agar tercih edilmiştir. Bu çalışmada, kanal içinde sodyum hipoklorit ve kan varlığında apeks bulucunun (Root ZX) etkinliğini değerlendirmişler ve çalışmanın sonucunda sodyum hipoklorit grubunun kan grubuna göre daha tutarlı sonuçlar verdiğini rapor etmişlerdir. ${ }^{39}$ 2008 yılında Briseno-Marroquin ve ark.'nın yaptığı çalışmada 4 farklı EAB'nin [Elements Apex Locator, Justy II (Hager \& Werke $\mathrm{GmbH}$, Duisburg, Almanya), Raypex 5, ve ProPex II (Dentsply Maillefer, İsviçre)] etkinliği değerlendirilirken, test ortamı olarak agar agar kullanılmıştır. EAB'ler arasında gerçek çalışma boyutu ile elektronik ölçüm boyutu arasında önemli bir fark bulunmamıştır. ${ }^{40}$

\section{Çiçek Süngeri}

Çiçek süngeri in vitro apeks bulucu çalışmalarında iskelet görevi yapar ve asıl elektro-iletken madde salin solüsyonudur. Süngerin elektro-iletkeni ile apikal daralım bölgesi arasında ideal temas sağlanamamaktadır. ${ }^{7}$ Sünger salin içine batırılmış olsa da, fiziksel özellikleri nedeniyle, sünger parçaları yalıtkan özellik gösterebilir. Böylece elektro-iletken ortamla eğenin teması apikal daralımın dışında gerçekleşebilir. Baldi ve ark. en fazla taşkın ölçüm sonucu veren test ortamının salin emdirilmiş çiçek süngeri olduğunu bildirmişlerdir. ${ }^{7}$ De Moor ve ark. dört apeks bulucunun doğruluğunu jelatin ve sodyum hipoklorit emdirilmiş sünger modelinde araştırmışlardır. In vitro test ortamı için jelatinin, sodyum hipokloritli süngerden daha uygun olduğunu bulmuşlardır. ${ }^{41}$

\section{SONUÇLAR}

Literatürde in vitro apeks bulucu çalışmalarında farklı test ortamları kullanılmaktadır. Bütün test ortamlarının ortak özelliği elekro-iletken olmaları ve periapikal dokuları taklit ederek apeks bulucunun elektrik devresini tamamlamalarıdır. Aljinat, sahip olduğu pek çok avantaj sebebiyle literatürde en çok tercih edilen ortam materyali olmakla beraber, bu ortamların etkinliklerinin birbirleri ile karşılaştırmasını yapan daha çok çalışmaya intiyaç bulunmaktadır.

Bu çalışma, çalışmayı yürüten tüm yazarlar tarafindan okunmuş ve onaylanmış orijinal bir çalışmadır. Herhangi bir yazar, kurum ya da kuruluş ile çıkar çatışması olmadığını belirtilmek isteriz. 


\section{KAYNAKLAR}

1. Ricucci D. Apical limit of root canal instrumentation and obturation, part 1. Literature review. Int Endod J 1998;31:384-93.

2. Estrela C, Holland $R$, Estrela $C R$, Alencar $A H$, Sousa-Neto MD, Pecora JD. Characterization of successful root canal treatment. Braz Dent J 2014;25:3-11.

3. Ali R, Okechukwu NC, Brunton P, Nattress B. An overview of electronic apex locators: Part $1 . \mathrm{Br}$ Dent J 2013;214:155-8.

4. Czerw RJ, Fulkerson MS, Donnelly JC. An in vitro test of a simplified model to demonstrate the operation of electronic root canal measuring devices. J Endod 1994;20:605-6.

5. Custer LE. Exact methods of locating the apical foramen. J Nat Dent Ass 1918;5:815-9.

6. Sunada I. New method for measuring the length of the root canal. J Dent Res 1962;41:375-87.

7. Baldi JV, Victorino FR, Bernardes RA, de Moraes IG, Bramante CM, Garcia RB, Bernardinelli N. Influence of embedding media on the assessment of electronic apex locators. J Endod 2007;33:4769.

8. Ibarrola JL, Chapman BL, Howard JH, Knowles KI, Ludlow MO. Effect of preflaring on Root ZX apex locators. J Endod 1999;25:625-6.

9. Ozsezer E, Inan $U$, Aydin U. In vivo evaluation of ProPex electronic apex locator. J Endod 2007; 33: 974-7.

10. Ustun Y, Uzun O, Er O, Canakci BC, Topuz O. The effect of residual calcium hydroxide on the accuracy of a contemporary electronic apex locator. Acta Odontol Scand 2015;73:132-6.

11. Stober EK, de Ribot J, Mercade M, Vera J, Bueno $R$, Roig M, Duran-Sindreu F. Evaluation of the Raypex 5 and the Mini Apex Locator: an in vivo study. J Endod 2011;37:1349-52.

12. Serna-Pena G, Gomes-Azevedo S, Flores-Trevino J, Madla-Cruz E, Rodriguez-Delgado I, MartinezGonzalez G. In Vivo Evaluation of 3 Electronic Apex Locators: Root ZX Mini, Apex ID, and Propex Pixi. J Endod 2020;46:158-61.

13. Shabahang S, Goon WW, Gluskin AH. An in vivo evaluation of Root ZX electronic apex locator. J Endod 1996;22:616-8.

14. Meares WA, Steiman HR. The influence of sodium hypochlorite irrigation on the accuracy of the Root ZX electronic apex locator. J Endod 2002;28:595-8.
15. Abdelsalam N, Hashem N. Impact of Apical Patency on Accuracy of Electronic Apex Locators: In Vitro Study. J Endod 2020;46:509-14.

16. Jadhav GR, Mittal P, Patil V, Kandekar P, Kulkarni A, Shinde S, Syed S, Elahi S. Accuracy of Different Apex Locators in Teeth with Simulated Apical Root Resorption: an In Vitro Study. Folia Med 2018;60:624-31.

17. Abdelsalam N, Hashem N. Impact of Apical Patency on Accuracy of Electronic Apex Locators: In Vitro Study. J Endod 2020;46:509-14.

18. Cruz ATG, Wichnieski $C$, Carneiro $E$, da Silva Neto UX, Gambarini G, Piasecki L. Accuracy of 2 Endodontic Rotary Motors with Integrated Apex Locator. J Endod 2017;43:1716-9.

19. Johnston-Banks, F. A. Gelatin. In P. Harris (Ed.), Food gels. 1th. Crown House:1990.p.233-89.

20. Schrieber R, Gareis H. Gelatin handbook. Theory and industrial practice. 1th. Betz-druck $\mathrm{GmbH}$ : 2007.p.45-6

21. Nahmias Y, Aurelio JA, Gerstein H. An in vitro model for evaluation of electronic root canal length measuring devices. J Endod 1987;13:209-14.

22. Donnelly JC. A simplified model to demonstrate the operation of electronic root canal measuring devices. J Endod 1993;19:579-80.

23. Guise GM, Goodell GG, Imamura GM. In vitro comparison of three electronic apex locators. ] Endod 2010;36:279-81.

24. Mull JP, Manjunath V, Manjunath $M$. Comparison of accuracy of two electronic apex locators in the presence of various irrigants: An in vitro study. J Conserv Dent 2012;15:178-82.

25. Ching SH, Bansal N, Bhandari B. Alginate gel particles-A review of production techniques and physical properties. Crit Rev Food Sci Nutr 2017;57:1133-52.

26. Souza JM, Caldas AL, Tohidi SD, Molina J, Souto AP, Fangueiro R, Zille A. Properties and controlled release of chitosan microencapsulated limonene oil. Rev Bras Farmacogn 2014;24. p.691-8.

27. Tian AL, Li XC, Lu YT, Ye JJ, Liu Y, He L. The effect of curvatures on the accuracy of the electronic apex locator. Shanghai Kou Qiang Yi Xue 2014;23:685-8.

28. Puri N, Chadha R, Kumar P, Puri K. An in vitro comparison of root canal length determination by DentaPort ZX and iPex apex locators. J Conserv Dent 2013;16:555-8. 
29. Nazarimoghadam K, Labaf H. Evaluation of Two New Electronic Apex-Locator-Controlled Handpieces Using a NiTi Rotary File: An In Vitro Study. J Dent 2013;10:501-5.

30. Lipski M, Trąbska-Świstelnicka M, Woźniak K, Dembowska $E$, Droździk A. Evaluation of alginate as a substitute for root-surrounding tissues in electronic root canal measurements. Aust Endod J 2013;39:155-8.

31. Gehlot PM, Manjunath V, Manjunath MK. An in vitro evaluation of the accuracy of four electronic apex locators using stainless-steel and nickeltitanium hand files. Restor Dent Endod 2016;41:611.

32. Khatri MP, Ghivari SB, Pujar M, Faras R, Gopeshetti $P$, Vanti A. Accuracy of two electronic apex locators in locating root perforations in curved canals in dry and wet conditions: A comparative in vitro study. J Dent Res 2019;16:407-12.

33. Çiçek E, Bodrumlu E. Kök Kanalında Farklı İrrigasyon Solüsyonları Varlığında Yeni Nesil Apeks Bulucu Cihazların Değerlendirilmesi. J Dent Fac Atatürk Uni 2013;21:37-42.

34. Ushiyama J. New principle and method for measuring the root canal length. J Endod 1983;9:97-104.

35. Zand V, Rahimi S, Davoudi P, Afshang A. Accuracy of Working Length Determination using NovApex and Root-ZX Apex Locators: An in vitro Study. J Contemp Dent Pract 2017;18:383-5.

36. Nekoofar MH SK, Sadighi Akha E, Namazikhah MS. The accuracy of the Neosono Ultima EZ apex locator using files of different alloys: an in vitro study. J Calif Dent Assoc 2002;30:681-4.

37. Bixler $\mathrm{HJ}$, Porse H. (2011). A decade of change in the seaweed hydrocolloids industry. Journal of Applied Phycology 2011;23: 321-35.

38. Guerreiro-Tanomaru JM, Croti HR, Silva GF, Faria G, Tanomaru-Filho $M$. Tooth embedding medium influences the accuracy of electronic apex locator. Acta Odontol Latinoam 2012;25:214-7.

39. AK Ebrahim TY, C Kobayashi, H Suda. The effects of file size, sodium hypochlorite and blood on the accuracy of Root ZX apex locator in enlarged root canals: an in vitro study. Aust Dent J 2006;51:1537.

40. Briseno-Marroquin B, Frajlich S, Goldberg F, Willershausen $B$. Influence of instrument size on the accuracy of different apex locators: an in vitro study. J Endod 2008;34:698-702.
41. De Moor RJ, Hommez GM, Martens LC, De Boever JG. Accuracy of four electronic apex locators: an in vitro evaluation. Endod Dent Traumatol 1999;15:77-82.

\section{Sorumlu Yazarın Yazışma Adresi}

Arş. Gör. Hamza CUDAL

Erciyes Üniversitesi, Diş Hekimliği Fakültesi, Endodonti Anabilim Dalı, Melikgazi /

Kayseri / TÜRKİYE

Tel: 05058425452

E-mail:hamzacudal@hotmail.com 